\title{
INCOMPLETE COST PASS-THROUGH UNDER DEEP HABITS
}

\author{
Morten Ravn \\ Stephanie Schmitt-Grohe \\ Martin Uribe \\ Working Paper 12961 \\ http://www.nber.org/papers/w12961
NATIONAL BUREAU OF ECONOMIC RESEARCH
1050 Massachusetts Avenue
Cambridge, MA 02138
March 2007

We thank for comments seminar participants at Duke University. The views expressed herein are those of the author(s) and do not necessarily reflect the views of the National Bureau of Economic Research.

(C) 2007 by Morten Ravn, Stephanie Schmitt-Grohe, and Martin Uribe. All rights reserved. Short sections of text, not to exceed two paragraphs, may be quoted without explicit permission provided that full credit, including $(\subset$ notice, is given to the source. 
Incomplete Cost Pass-Through Under Deep Habits

Morten Ravn, Stephanie Schmitt-Grohe, and Martin Uribe

NBER Working Paper No. 12961

March 2007

JEL No. D11,D4,L1

\begin{abstract}
A number of empirical studies document that marginal cost shocks are not fully passed through to prices at the firm level and that prices are substantially less volatile than costs. We show that in the relative-deep-habits model of Ravn, Schmitt-Grohe, and Uribe (2006), firm-specific marginal cost shocks are not fully passed through to product prices. That is, in response to a firm-specific increase in marginal costs, prices rise, but by less than marginal costs leading to a decline in the firm-specific markup of prices over marginal costs. Pass-through is predicted to be even lower when shocks to marginal costs are anticipated by firms. In our model, unanticipated firm-specific cost shocks lead to incomplete pass-through (or a decline in markups) of about 20 percent and anticipated cost shocks are associated with incomplete pass-through of about 50 percent. The model predicts that cost pass-through is increasing in the persistence of marginal cost shocks and U-shaped in the strength of habits. The relative-deep-habits model implies that conditional on marginal cost disturbances, prices are less volatile than marginal costs.
\end{abstract}

Morten Ravn

Department of Economics

European University Institute

Villa San Paolo

Via della Piazzuola 43

50133 Florence

Italy

morten.ravn@eui.eu

Stephanie Schmitt-Grohe

Department of Economics

Duke University

P.O. Box 90097

Durham, NC 27708

and NBER

grohe@duke.edu
Martin Uribe

Department of Economics

Duke University

Durham, NC 27708-0097

and NBER

uribe@duke.edu 


\section{Introduction}

A number of empirical studies document that marginal cost shocks are not fully passed through to prices at the firm level. The observed sluggish response of prices to cost disturbances is also reflected in prices being substantially less volatile than costs. See for instance Goldberg (1995) for the automobile industry, Kadiyali (1997) for the photographic film industry, Hellerstein (2004) for the beer industry, and Nakamura (2006) for the coffee industry.

This paper develops a theoretical explanation for the observed incomplete pass-through of marginal cost disturbances to prices. The central element of our proposed theory is habit formation at the level of individual goods. In particular, we consider the model of external relative deep habits due to Ravn, Schmitt-Grohé, and Uribe (2006). When habits are formed on a good-by-good basis, the demand function for an individual good depends not only upon its relative price but also on past consumption of that good. This is because demand depends positively on the stock of habit, and the stock of habit, in turn, is an increasing function of past consumptions. A consequence of allowing for good-specific habit formation is that the profit maximization problem of the firm becomes dynamic. For higher current sales generate revenue not only in the current period but also in future periods by raising future habitual demand. Firms take this intertemporal connection of revenues into account in their price setting decision.

We show that a temporary increase in marginal costs induces firms to increase prices less than proportionally resulting in lowered markups. Firms find it optimal to narrow profit margins in the current period to limit the decline in future habitual demand triggered by the price increase. It follows that firms pass on only a fraction of the increase in marginal costs they experience. That is, in the deep habit model developed in this paper cost pass-through is incomplete. The dampened response of prices to marginal cost shocks results in prices being less volatile than marginal costs. Our emphasis on markup adjustments in explaining incomplete pass-through is in line with the available empirical evidence. Hellerstein (2004), for instance, finds that 68 percent of incomplete cost pass-through in the beer industry is explained by markup adjustments. Nakamura (2006) attributes a smaller but still sizable role to markup adjustments in explaining the response of prices to marginal cost shocks in the coffee industry.

We find that pass-through increases with the persistence of marginal cost shocks. The reason is that when the cost increase is more persistent, it is less valuable for the firm to maintain the size of its customer base, as production conditions are expected to be unfavorable for a number of periods. A consequence of the positive relationship between pass-through and the persistence of cost shocks is that the ratio of price volatility to marginal-cost volatility 
also increases with the persistence of cost shocks.

Our deep-habit model predicts that anticipation of marginal cost disturbances exacerbates incomplete pass-through. The reason is that when firms learn about a future cost increase they find it optimal to gradually adjust prices upward as a way to disinvest in customer base. Consequently, the required increase in prices at the time the shock is actually realized is smaller than it would have been had the shock been unanticipated.

Our theoretical model of incomplete cost pass-through is related to a number of existing studies. All of these studies share as the central transmission mechanism a demand function that depends proportionally on a measure of past sales. Phelps and Winter (1970) develop a model of customer markets, by assuming that current demand is proportional to the firm's market share in the previous period. Klemperer (1987, 1995), Froot and Klemperer (1989), and Kleshchelski and Vincent (2007) assume that customers face a fixed cost of switching suppliers. Thus, the current propensity to consume a particular good depends in part on past consumption of that good. Of these papers, the one most closely related to our study is Kleshchelski and Vincent (2007), as it focuses on the effects of firm-specific marginal cost shocks. An important difference between switching cost models and our deephabit formulation is that in the deep habit model there is gradual substitution between differentiated goods, rather than discrete switches among suppliers. One advantage of this, from the point of view of analytical tractability, is that under the deep-habit formulation one does not face an aggregation problem. Buyers can distribute their purchases identically and still suppliers face a gradual loss of customers if they raise their relative prices.

In all of the related theoretical studies just cited as well as in ours, it is important for the prediction of incomplete cost pass-through that past sales (or a function thereof) enter the demand function in a multiplicative fashion. In fact, we show that if past sales enter in an additive rather than multiplicative fashion, the model no longer predicts incomplete passthrough. The reason is that under an additive specification the aforementioned intertemporal effect of deep habits is offset by a static price-elasticity effect.

The remainder of the paper is organized in five sections. Section 2 presents a preference specification in which habits are good-specific, external to the household, and relative. It also derives the demand functions for individual goods. Section 3 characterizes the dynamic pricing problem of the firm. Section 4 presents the main results of the paper regarding incomplete pass-through of marginal cost shocks. Section 5 establishes that when habits enter additively in the demand for individual goods, incomplete pass-through fails to obtain. Section 6 concludes. 


\section{Demand with Good-Specific Habits}

Consider an economy populated by a continuum of identical households of measure one indexed by $j \in[0,1]$. Each household $j$ has preferences defined over consumption of a continuum of differentiated consumption goods, $c_{i t}^{j}$ indexed by $i \in[0,1]$. Following Ravn, Schmitt-Grohé, and Uribe (2006), preferences feature habit formation at the level of individual goods, or deep habits. We assume that habits are of the relative external type. That is, for each good variety $i$, households derive utility from a quasi-ratio of current consumption to a measure of lagged aggregate consumption. Specifically, household $j$ derives utility from an object $x_{t}^{j}$ defined by

$$
x_{t}^{j}=\left[\int_{0}^{1}\left(\frac{c_{i t}^{j}}{s_{i t-1}^{\theta}}\right)^{1-\frac{1}{\eta}} d i\right]^{\frac{1}{1-\frac{1}{\eta}}}
$$

where $s_{i t-1}$ denotes the stock of external habit in good $i$ in period $t-1$, which the household takes as exogenously given. The parameter $\eta>0$ denotes the intratemporal elasticity of substitution of habit-adjusted consumption of different varieties. The parameter $\theta$ measures the degree of time nonseparability in consumption of each variety. When $\theta=0$, we have the benchmark case of time separable preferences.

The stock of habit is assumed to evolve according to the following law of motion

$$
s_{i t}=\rho s_{i t-1}+(1-\rho) c_{i t},
$$

where

$$
c_{i t} \equiv \int_{0}^{1} c_{i t}^{j} d j
$$

denotes the aggregate per capita level of consumption of variety $i$, which the household takes as exogenously given. The parameter $\rho \in[0,1)$ measures the speed of adjustment of the stock of external habit to variations in the cross-sectional average level of consumption of variety $i$. When $\rho$ takes the value zero, the stock of habit is simply given by past consumption of $\operatorname{good} i$.

For any given level of $x_{t}^{j}$, purchases of each variety $i \in[0,1]$ in period $t$ must solve the problem of minimizing total expenditure,

$$
\int_{0}^{1} P_{i t} c_{i t}^{j} d i
$$

subject to the aggregation constraint (1), where $P_{i t}$ denotes the price of good $i$. The optimal 
level of $c_{i t}^{j}$ for $i \in[0,1]$ is then given by

$$
c_{i t}^{j}=\left(\frac{P_{i t}}{P_{t}}\right)^{-\eta} s_{i t-1}^{\theta(1-\eta)} x_{t}^{j},
$$

where

$$
P_{t} \equiv\left[\int_{0}^{1}\left(P_{i t} s_{i t-1}^{\theta}\right)^{1-\eta} d i\right]^{\frac{1}{1-\eta}}
$$

is a price index such that at the cost-minimizing consumption allocation

$$
P_{t} x_{t}^{j}=\int_{0}^{1} P_{i t} c_{i t}^{j} d i
$$

The case of habit formation emerges when, ceteris paribus, the demand for a particular variety is increasing in the stock of habit associated with that variety. That is, when $\theta(1-$ $\eta)>0$. In the absence of deep habits, $\eta$ must be greater than one in order for the monopolist problem to be well defined. We maintain this assumption here in order to be able to compare the dynamic implications of our model with and without deep habits. It follows that habit formation obtains only if $\theta$ is negative.

An alternative way to visualize that habit formation requires $\theta(1-\eta)>0$ is to examine the household optimality condition according to which the marginal rate of substitution of good $i$ for good $k$ is equated to their relative price. For the preferences given in equation (1) this optimality condition takes the form

$$
\left(\frac{c_{i t}^{j}}{c_{k t}^{j}}\right)^{-\frac{1}{\eta}}\left(\frac{s_{i t-1}}{s_{k t-1}}\right)^{\frac{\theta(1-\eta)}{\eta}}=\frac{P_{i t}}{P_{k t}} .
$$

Clearly, for the marginal rate of substitution of good $i$ for good $k$ to be increasing in the stock of habit of good $i$, it is necessary that $\theta(1-\eta)$ be positive. Accordingly, for the remainder of this paper we will assume that $\theta \leq 0$.

Integrating the individual demand functions for good $i$ over all households, one obtains the following aggregate demand function for good $i$ :

$$
c_{i t}=\left(\frac{P_{i t}}{P_{t}}\right)^{-\eta} s_{i t-1}^{\theta(1-\eta)} x_{t},
$$

where $x_{t} \equiv \int_{0}^{1} x_{t}^{j} d j$ is a measure of aggregate demand. 


\section{Pricing To Habits}

We assume that each variety of goods is produced by a monopolistically competitive firm. The producer of good $i$ faces the demand function given in equation (4). Firms take the aggregate price index $P_{t}$ and the measure of aggregate demand $x_{t}$ as exogenously given. At the same time, firms internalize the fact that current sales affect the strength of future demand through the habit stock $s_{i t}$.

Because we are interested only in firm dynamics taking as given the aggregate state of the economy, given by $P_{t}$ and $x_{t}$, we simplify the demand function to:

$$
c_{i t}=A P_{i t}^{-\eta} s_{i t-1}^{\theta(1-\eta)}
$$

where $A$ is a positive constant.

The marginal cost of producing good $i$, denoted by $M C_{i t}$, is assumed to be exogenous and independent of scale. Then period profits of firm $i$ can be written as:

$$
\left(P_{i t}-M C_{i t}\right) c_{i t}
$$

An important implication of the presence of deep habits is that the pricing problem at the firm level becomes dynamic. Firms are assumed to discount future profits at the constant rate $\beta \in(0,1) .{ }^{1}$ The firm's problem consists in choosing processes for prices $P_{i t}$ and quantities $c_{i t}$ so as to maximize the present discounted value of profits, given by

$$
\sum_{t=0}^{\infty} \beta^{t} E_{0}\left(P_{i t}-M C_{i t}\right) c_{i t}
$$

subject to the law of motion for the stock of habit and the demand function for good $i$, given in equations (2) and (5), respectively, and taking as given the exogenous process for $M C_{i t}$ and the initial stock of habit $s_{i_{-1}}$.

To gain insight into the nature of the firm's incentives, we now concentrate on the simple case that the stock of habits fully depreciates after one period. That is, we focus on the case $\rho=0$ in equation (2), which implies that $s_{i t-1}=c_{i t-1}$. The first-order conditions associated with the firm's problem are the demand function

$$
c_{i t}=A P_{i t}^{-\eta} c_{i t-1}^{\theta(1-\eta)}
$$

\footnotetext{
${ }^{1}$ In Ravn, Schmitt-Grohé, and Uribe (2005, 2006) we analyze a general equilibrium model with relative deep habits. There, the discount factor of the firm is an endogenous variable given by the representative household's intertemporal marginal rate of substitution.
} 
and

$$
P_{i t}\left(1-\frac{1}{\eta}\right)+\beta \theta \frac{1-\eta}{\eta} E_{t} P_{i t+1} \frac{c_{i t+1}}{c_{i t}}=M C_{i t} .
$$

Optimality condition (7) can be interpreted as follows. The first term on the left-hand side, $P_{i t}(1-1 / \eta)$, is the classical expression for marginal revenue in the static monopoly problem. In the absence of deep habits (i.e., when $\theta=0$ ), this standard measure of marginal revenue is equated to the marginal cost, $M C_{i t}$, appearing on the right-hand side. The second term on the left-hand side, $\beta \theta \frac{1-\eta}{\eta} E_{t} P_{i t+1} \frac{c_{i t+1}}{c_{i t}}$, can be interpreted as the future marginal revenue stemming from a sale today. This extra marginal revenue is habitual in nature. For higher current sales increase the stock of habits thereby raising future demand. Specifically, the second term on the left-hand side represents the present value of profits in period $t+1$ generated by a unit increase in $c_{i t}$ holding constant $c_{i t+j}$ for all $j \geq 1$, and $P_{i t+j}$ for all $j \geq 2$,

and increasing $P_{i t+1}$ appropriately. Because under this calculus of variation argument future expected sales are held constant, no future marginal costs enter in the optimality condition.

It follows from equation (7) that the markup of prices over marginal cost, which we denote by

$$
\mu_{i t} \equiv P_{i t} / M C_{i t}
$$

is time varying. That is, deep habits gives rise to a theory of endogenous markup determination at the firm level. Rearranging optimality condition (7), yields the following expression for the markup:

$$
\mu_{i t}=\frac{1}{1-\frac{1}{\eta}+\beta \theta \frac{1-\eta}{\eta} E_{t} \frac{P_{i t+1} c_{i t+1}}{P_{i t} c_{i t}}} .
$$

According to this expression, firms set markups below average whenever sales revenues are expected to grow. The sensitivity of the markup to expected future revenue growth is higher the higher the degree of habit formation - i.e., the larger is $\theta$ in absolute value - and the more patient firms are-i.e., the larger is the discount factor $\beta$.

\subsection{Steady-State Markup}

Under deep habits the steady-state markup is no longer governed by a single parameter, namely the price elasticity of demand $\eta$, but depends on the degree of habit formation $\theta$ as well as on the discount factor $\beta$. Specifically, the steady-state markup is given by

$$
\mu=\frac{1}{1-\frac{1}{\eta}+\beta \theta \frac{1-\eta}{\eta}}<\frac{1}{1-\frac{1}{\eta}} .
$$


The inequality highlights that under deep habits the steady-state markup is smaller than in the standard static monopolistic case, in which the markup equals $1 /(1-1 / \eta)$. The reason the markup is lower is that under deep habits the long-run price elasticity of demand is larger than the short-run, or static, price elasticity. This is because under deep habits a price increase leads to demand losses not only in the current period but also in the future, as the weakening in habitual demand entails a loss in customer base. For sufficiently large absolute values of $\theta$, the steady-state markup becomes less than unity, implying long-run pricing below marginal cost. We rule out this possibility and require that $\mu$ be larger than one. This restriction imposes the following constraint on the habit parameter $\theta$ :

$$
\theta(1-\eta)<\frac{1}{\beta}
$$

which we maintain throughout our analysis.

\subsection{Stability of Firm Dynamics}

In this section we derive the set of values of the parameter $\theta$, measuring the strength of good-specific habits, for which pricing dynamics are locally unique.

Combining optimality conditions (6) and (7) one obtains a second-order stochastic dif-

ference equation in $c_{i t}$ driven by the exogenous forcing process $M C_{i t}$. The variable $c_{i t-1}$ is a predetermined state in period $t$.

We limit the characterization of price and sales dynamics to stationary stochastic fluctuations that are expected to remain forever in a vicinity of and converge to the deterministic steady sate. Letting $\hat{x}_{t} \equiv \ln \left(x_{t} / x\right)$ denote the $\log$ deviation of the variable $x_{t}$ from its deterministic steady-state value $x$, the evolution of the quantity sold can be written up to a first-order approximation as

$$
\left[\begin{array}{c}
E_{t} \hat{c}_{i t+1} \\
\hat{c}_{i t}
\end{array}\right]=A\left[\begin{array}{c}
\hat{c}_{i t} \\
\hat{c}_{i t-1}
\end{array}\right]+B \widehat{M C}_{i t} .
$$

Local uniqueness of the firm's pricing dynamics requires that the matrix $A$ have one root inside the unit circle and one root outside the unit circle. One can show that if the steadystate markup is greater than one (i.e., if restriction (8) holds), then local uniqueness of firm dynamics obtains if and only if:

$$
\theta(1-\eta)<1
$$

The left-hand side of this condition represents the elasticity of current demand with respect to the stock of habit (see equation (4)). Thus, the restriction says that an increase in current 
demand must raise future demand less than proportionally, holding future prices constant.

\section{Incomplete Pass-Through}

Pass-through of marginal cost shocks is said to be incomplete if a one-percent increase in marginal cost leads to a less-than-one-percent increase in prices. Equivalently, passthrough is incomplete when markups decline in response to an increase in marginal costs. To ascertain whether in our pricing-to-habit model pass-through is incomplete, we characterize the impulse response of prices and markups to innovations in marginal costs.

We assume that the logarithm of marginal costs follows a univariate autoregressive process of order one. Formally,

$$
\widehat{M C}_{i t+1}=\lambda \widehat{M C}_{i t}+\epsilon_{t+1},
$$

where $\lambda \in[0,1)$ denotes the serial correlation of marginal costs and $\epsilon_{t}$ is an i.i.d. shock with mean zero and standard deviation $\sigma_{\epsilon}$.

We parameterize the model using a quarter as the time unit. We set the firm's discount factor $\beta$ equal to 0.99 , so that the rate at which profits are discounted is 4 percent per year. We assume a value of 6 for $\eta$, the intratemporal elasticity of substitution across goods varieties. This value implies that in the absence of pricing to habits (i.e., when $\theta=0$ ), the steady-state markup equals 20 percent, or $\mu=1.2$. We set the deep-habit parameter $\theta$ to -0.1. This value together with the one assigned to $\eta$ implies that the elasticity of demand with respect to the stock of habit is $1 / 2$ and that the steady-state markup is 9 percent.

To highlight the role of pricing to habits in propagating the effect of marginal cost disturbances, we initially restrict attention to a purely temporary increase in $M C_{i t}$ by setting the parameter $\lambda$ equal to zero. We approximate the firm's price dynamics by log-linearizing the firm's optimality conditions around the nonstochastic steady state.

Table 1 displays the response of prices and marginal costs to a purely temporary onepercent increase in marginal costs. In the period of impact, the firm increases prices but proportionally less than the increase in the marginal cost. Only 81 percent of the increase in marginal costs are passed through to product prices. As a result, the markup of prices over marginal cots declines by 19 percent. The resulting incomplete pass-through is the consequence of an intertemporal tradeoff: Increasing current prices prevents the erosion of current profit margins. At the same time, it leads to a decline in current sales and hence a corresponding reduction in the stock of habits, which weakens the strength of future demand. One period after the shock, marginal costs are back to their steady-state value. However, markups are not. Firms need to rebuild their customers' stock of habit, which had declined 
Table 1: Response to a Temporary Increase in Marginal Cost

\begin{tabular}{cccccc}
\hline \hline & & \multicolumn{2}{c}{$\begin{array}{c}\text { Pricing To Habits } \\
(\theta=-0.1)\end{array}$} & \multicolumn{2}{c}{$\begin{array}{c}\text { No Habits } \\
(\theta=0)\end{array}$} \\
Period & Marginal Cost & Price & Markup & Price & Markup \\
\hline 0 & 1 & 0.81 & -0.19 & 1 & 0 \\
1 & 0 & -0.11 & -0.11 & 0 & 0 \\
2 & 0 & -0.04 & -0.04 & 0 & 0 \\
3 & 0 & -0.01 & -0.01 & 0 & 0 \\
\hline \hline
\end{tabular}

Note: Marginal costs, prices, and markups are measured in percent deviations from their respective steady-state values.

after the initial price hike. To this end, firms keep markups below average along the entire transition. This transition can be interpreted as a pure investment in customer base. The cost of this investment is a sequence of below-average per unit profits.

The firm's dynamics in the absence of habits is quite different. As shown in the last two columns of table 1, prices move one for one with marginal costs and markups are unaffected by the cost disturbance. Without a habit stock to maintain, the firm faces no intertemporal tradeoff, but simply a static, isoelastic demand function. Thus, in the absence of habits markups are constant at all times and dictated by the price elasticity of demand $\eta$.

\subsection{Anticipated Cost Shocks}

Pass-through can appear to be even more incomplete when marginal cost disturbances are anticipated. This is because firms find it optimal to increase prices already at the time they learn about the arrival of a future cost shock. By the time the shock is actually realized, demand is already weakened by a smaller habit stock, mitigating the incentive to contain sales via higher prices. Table 2 displays the response of prices and markups to an anticipated temporary one-percent increase in marginal costs. The table also reproduces from table 1 the responses of prices and marginal costs when the cost shock is unanticipated. The shock is realized in period 0 . At that date, prices increase by only 0.48 percent with respect to period - 1 in response to a one-percent anticipated increase in marginal costs. By contrast, when the shock is unanticipated, the increase in prices in period 0 is 0.81 percent. It follows that in this example when the cost increase is anticipated pass-through falls significantly. Finally, we note that in the absence of good-specific habit formation, pass-through is perfect, regardless of whether the cost shock is anticipated or unanticipated. 
Table 2: Response to an Anticipated Temporary Increase in Marginal Cost

\begin{tabular}{cccccc}
\hline \hline & & \multicolumn{2}{c}{ Anticipated } & \multicolumn{2}{c}{ Unanticipated } \\
Period & Marginal Cost & Price & Markup & Price & Markup \\
\hline-1 & 0 & 0.29 & 0.29 & 0 & 0 \\
0 & 1 & 0.77 & -0.23 & 0.81 & -0.19 \\
1 & 0 & -0.12 & -0.12 & -0.11 & -0.11 \\
2 & 0 & -0.05 & -0.05 & -0.04 & -0.04 \\
3 & 0 & -0.02 & -0.02 & -0.01 & -0.01 \\
\hline \hline
\end{tabular}

Note: Marginal costs, prices, and markups are measured in percent deviations from their respective steady-state values.

\subsection{Persistent Cost Shocks}

Thus far, we have limited attention to the case of purely temporary cost shocks. We now explore the relationship between pass-through and the degree of persistence in the marginal cost process. In the $\mathrm{AR}(1)$ specification given in equation (10), persistence is governed by the parameter $\lambda$. Figure 1 displays the impact effect of a one-percent increase in marginal costs on the markup as a function of $\lambda$. Pass-through is increasing in the persistence of the shock: the more persistent the shock is, the larger is the initial price increase in response to a one-percent increase in marginal costs. Intuitively, if marginal cost shocks are temporary, firms are reluctant to pass the cost increase on to prices to avoid erosion of their customer base, as they expect costs to go back down quickly to their normal level. On the other hand, if the cost shock is persistent, firms do not mind losing customers because cost conditions are not favorable for production. For this reason, they choose to pass on a larger fraction of the marginal cost increase to prices. If the cost shock is sufficiently persistent (in our example when $\lambda$ is greater than 0.5 ), then firms find it optimal to pass through to prices more than the entire increase in marginal costs, resulting in an increase in markups.

\subsection{The Price-Cost Volatility Ratio}

Empirical studies have documented that marginal costs tend to be more volatile than product prices. Nakamura (2006), for instance, studies pass through of changes in coffee commodity costs to coffee retail and wholesale prices. She finds that over the past decade commodity coffee prices have exhibited much higher volatility than retail and wholesale coffee prices.

The fact that under good-specific habit formation pass-through of marginal costs to prices is incomplete, suggests that prices might be less volatile than marginal costs at the 
Figure 1: Pass-Through and Persistence of Cost Shocks

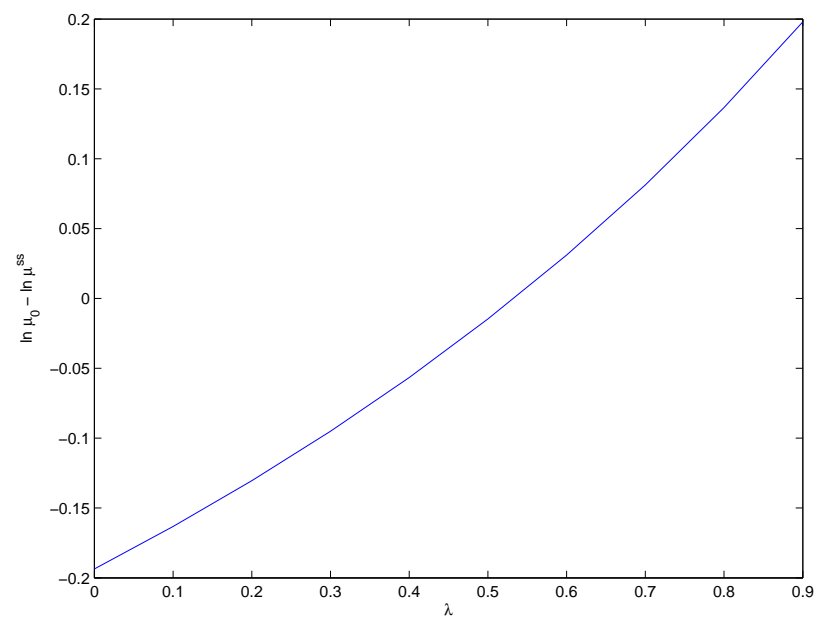

Note: The vertical axis measures the percent deviation of the markup from steady state in the period of impact of a one-percent increase in marginal cost. The horizontal axis measures the degree of persistence of marginal costs.

firm level. This is indeed the case. Figure 2 displays the ratio of the standard deviation of prices, denoted $\sigma_{p}$, to the standard deviation of marginal costs, denoted $\sigma_{m c}$, as a function of the serial correlation of marginal costs, $\lambda$. When the cost shock is purely temporary, the price-cost volatility ratio is 0.82 , implying that prices are about 20 percent less volatile than marginal cots. The price-cost volatility ratio increases with the persistence of the shock, but remains below unity for all values of $\lambda$ in $[0,1)$. It is remarkable that prices are less volatile than marginal costs for values of $\lambda$ above 0.5 , because for this range of values firms pass-through more than one hundred percent of marginal cost innovations on impact (see figure 1). The reason why prices continue to be less volatile than marginal costs when marginal costs are highly persistent is that although markups increase on impact when the firm is hit with an unexpected increase in marginal cost, prices converge to their long-run value faster than marginal costs resulting in the latter being above the former along most of the transition. The reason for the faster convergence of prices is the firm's desire to rebuild the stock of habits by charging below-average markups shortly after a shock realization.

\subsection{Pass-Through and the Strength of Habits}

Figure 3 displays the impact effect on the markup of a temporary increase in marginal cost as a function of the parameter governing the strength of habits, $|\theta|$. Habits are stronger the 
Figure 2: The Price-Cost Volatility Ratio

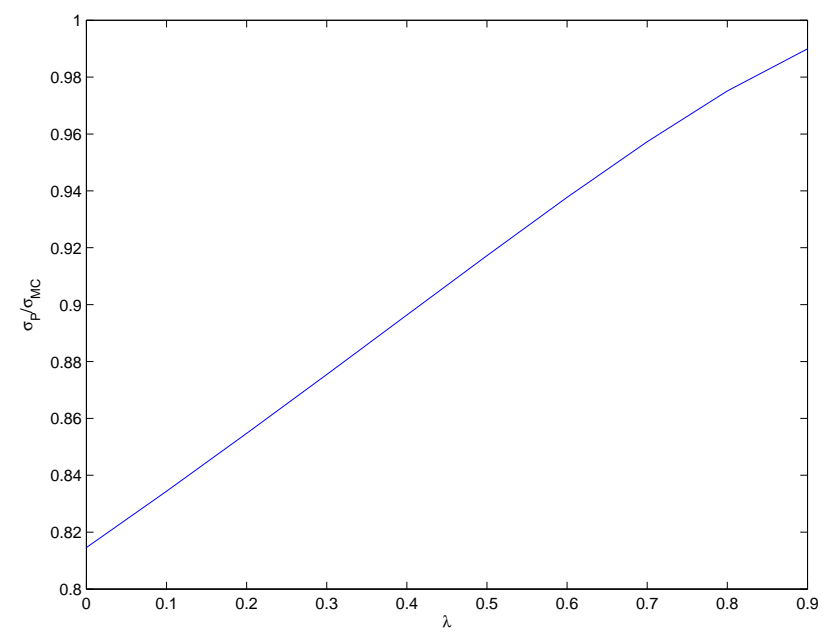

Note: $\sigma_{p}$ and $\sigma_{m c}$ denote, respectively, the standard deviations of prices and marginal costs. The parameter $\lambda$ measures the persistence of the marginal-cost shock.

Figure 3: Pass-Through and the Strength of Habits

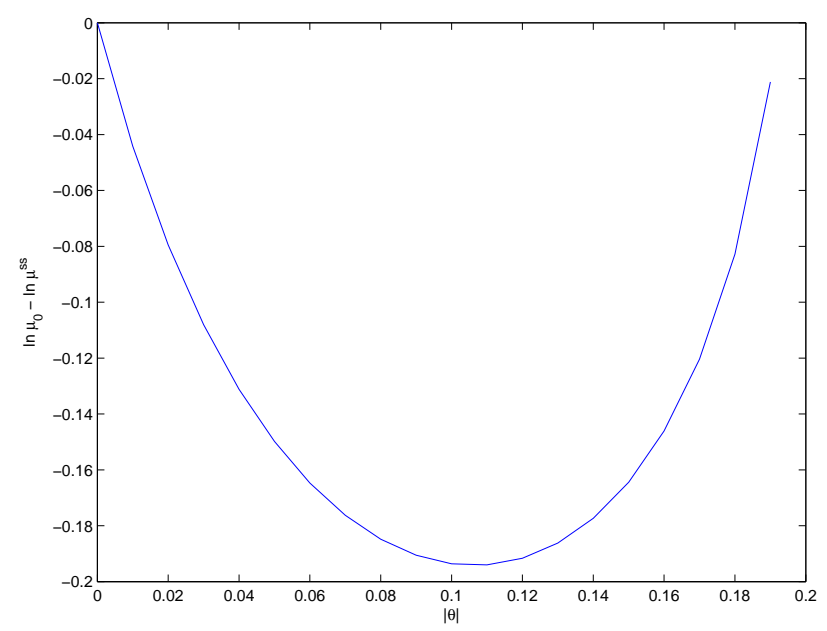

Note: The vertical axis measures the percent deviation of the markup from steady state in the period of impact of a one-percent temporary increase in marginal cost. The horizontal axis measures the degree of habit persistence. 
larger is $\theta$ in absolute value. The largest possible value of $|\theta|$ for which the firm's dynamics are locally unique and the long-run markup is positive is $1 /(\eta-1)$, which under our calibration imposes an upper bound of 0.2 on $|\theta|$. This range of values of $|\theta|$ may seem narrow. However, recall that the habit elasticity of demand is given by $\theta(1-\eta)$, rather than just $\theta$. Therefore, as $|\theta|$ varies from 0 to 0.2 , the habit elasticity of demand ranges from 0 to 1.

The figure shows that for $|\theta|=0$, or in the absence of deep habits, pass-through is complete. In this case, the markup of prices over marginal cost is unchanged by the innovation in marginal cost, implying that prices increase proportionally with marginal costs. The figure also shows that for all positive admissible values of $|\theta|$, the markup falls in response to an increase in marginal costs. That is, under deep habits cost pass-through is incomplete for the entire admissible range of $|\theta|$.

Notably, there is a nonmonotone relationship between the extent of incomplete passthrough and the degree of habit formation. When habit formation is weak (i.e., at low absolute values of $\theta$ ) pass-though becomes more incomplete as $|\theta|$ increases. At a value of $|\theta|$ of about 0.1 incomplete pass-through reaches a maximum. When habits are strong (i.e., for values of $|\theta|>0.1$ ) pass-through becomes less incomplete as $|\theta|$ increases.

The nonmonotonic relationship between the strength of habit formation and the incompleteness of pass-through is due to the interaction of two opposing effects: the habit-elasticity effect and the price-elasticity effect. The habit-elasticity effect is given by the fact that as $|\theta|$ increases, the habit elasticity of demand, given by $\theta(1-\eta)$ rises, and therefore passing cost increases on to prices has a stronger negative effect on future demand. The habit-elasticity effect therefore tends to make pass-through more incomplete as $|\theta|$ rises. The price-elasticity effect is more subtle. It arises because when $|\theta|$ increases, the short-run price elasticity of demand, given by $\eta$, becomes relatively smaller than the long-run price elasticity of demand, given by $\eta /(1-\theta(1-\eta))$. This relative decrease in the short-run price elasticity of demand creates an incentive for firms to charge larger current markups, that is, to pass on to prices a larger fraction of marginal cost increases. The habit-elasticity and price-elasticity effects work in opposite directions. At low absolute values of $\theta$ the former effect dominates the latter, whereas at high absolute values of $\theta$ the latter dominates the former. The reason why the price-elasticity effect dominates for large values of $|\theta|$ is that the long-run price elasticity becomes arbitrarily large as $|\theta|$ approaches its upper limit $1 /(\eta-1)$.

\subsection{Perverse Pass-Through}

There are parameterization of the model for which the firm's response to an increase in marginal costs is a reduction in the price. Froot and Klemperer (1989) refer to such a 
response of prices to a marginal cost shock as 'perverse pass-through.' In the context of our model, perverse pass-through is a pathological case in the sense that it occurs only under parameterizations for which the steady-state markup is negative. Formally, one can establish the following result: If $\eta>1 / \beta$ and $\mu>1$, then perverse pass-through cannot be supported as a stationary solution to the firm's profit maximization problem. ${ }^{2}$ The condition $\eta>1 / \beta$ is quite weak. For example, in the calibration exercise of this section, it is satisfied whenever the markup is below nine thousand percent, an astronomically large number. It follows from this result that firms will always increase prices in response to an upward innovation in marginal costs.

\section{Additive Habits}

It is of interest to ascertain whether the incomplete pass-through prediction of the model analyzed thus far depends on the particular way in which past sales affect current demand conditions. Froot and Klemperer (1989), for instance state that quite generally any model in which past sales increase current demand will generate the prediction of incomplete pass through. In their words, "we need not impose a specific demand function or reason why market share matters. The effects that we isolate in this way are therefore very general and transcend the particularities of simple models that can be solved explicitly" (p. 640).

We examine the sensitivity of our incomplete pass-through result to an alternative specification of the demand function. This alternative specification originates in a different assumption about the way habits affect period utility than the one maintained in section 2 . Specifically, following Ravn, Schmitt-Grohé, and Uribe (2006), we assume that habits are of the additive external type. That is, for each good variety $i$, households derive utility from a quasi-difference of current consumption to a measure of lagged aggregate consumption. Household $j$ derives utility from an object $x_{t}^{j}$ defined by

$$
x_{t}^{j}=\left[\int_{0}^{1}\left(c_{i t}^{j}-\theta s_{i t-1}\right)^{1-\frac{1}{\eta}} d i\right]^{\frac{1}{1-\frac{1}{\eta}}}
$$

where $\theta \in[0,1)$ defines the degree of habit persistence. The optimal level of $c_{i t}^{j}$ for $i \in[0,1]$ is then given by

$$
c_{i t}^{j}=\left(\frac{P_{i t}}{P_{t}}\right)^{-\eta} x_{t}^{j}+\theta s_{i t-1},
$$

where $P_{t} \equiv\left[\int_{0}^{1}\left(P_{i t}\right)^{1-\eta} d i\right]^{\frac{1}{1-\eta}}$ is a price index. This individual demand function for good $i$

\footnotetext{
${ }^{2}$ The proof of this claim is available from the authors on request.
} 
Figure 4: Lack of Pass-Through Under Additive Habits

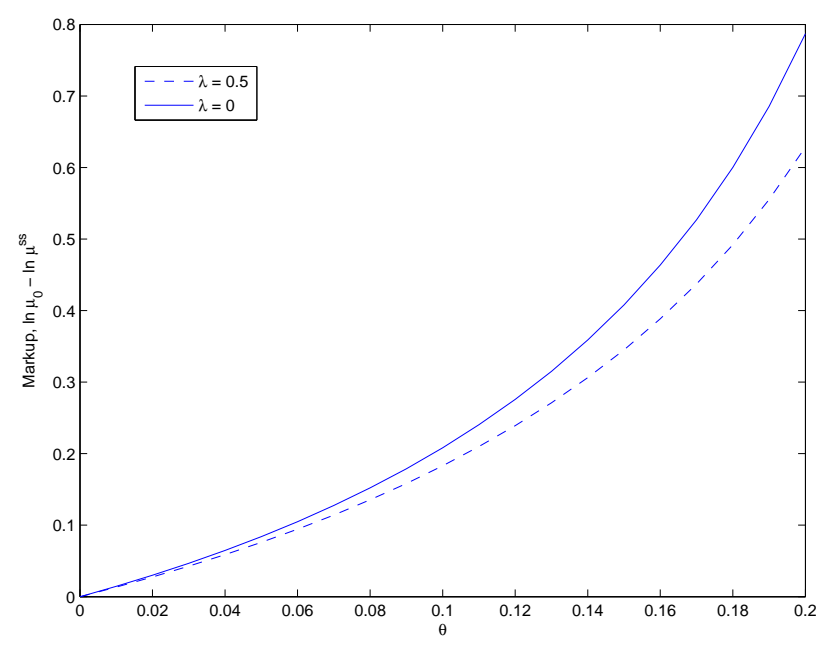

Note: The vertical axis measures the percent deviation of the markup from steady state in the period of impact of a one-percent increase in marginal cost. The horizontal axis measures the degree of habit persistence.

gives rise to the following aggregate demand for good $i$ :

$$
c_{i t}=\left(\frac{P_{i t}}{P_{t}}\right)^{-\eta} x_{t}+\theta s_{i t-1}
$$

The firm's optimization problem is identical to the one studied in section 3. Figure 4 displays with a solid line the impact effect on the markup of a one-percent increase in the marginal cost. The broken line displays the case of a persistent marginal-cost shock $(\lambda=0.5)$. The firm's dynamics are stable for values of $\theta$ between 0 and 0.25 . Contrary to what happens under relative habits, under additive habits, regardless of whether the shock is persistent or transitory, firms pass through on to prices more than the full increase in marginal cost. As a result, the markup increases in response to the innovation in marginal cost.

The intuition for why pass-through is predicted to be more than complete under additive habits can be developed by inspecting the demand function given in equation (11). The aggregate demand for good $i$ is the sum of a price elastic term, $\left(\frac{P_{i t}}{P_{t}}\right)^{-\eta} x_{t}$, with elasticity $\eta$, and a price inelastic term, $\theta s_{i t-1}$. The price inelastic term stems from the additive structure of habit formation. The price elasticity of demand is a weighted average of $\eta$ and 0 , with the weight on $\eta$ determined by the share of the price-elastic component of demand. Naturally, in response to the increase in marginal cost, the firm increases the price. To understand whether 
the price increase should be proportionally larger or smaller than the cost hike, notice that any increase in price reduces the relative size of the price elastic term in total demand. As a consequence, the price elasticity falls. Because the markup is inversely related to the price elasticity, the increase in marginal cost is associated with an increase in the desired markup.

The intertemporal effect of deep habits stressed in the relative-habit formulation of section 4 is still present in the additive-habit model. That is, firms have an incentive not to pass the full increase in costs on to price, to avoid losing customer base in the future, due to the erosion in habits. However, this intertemporal effect is dominated by the price-elasticity effect described in the previous paragraph, causing prices to rise by more than marginal costs.

\section{Discussion and Conclusion}

In this paper, we present a model of cost pass-through at the firm level that can explain qualitatively the empirical regularity that firm-specific cost disturbances are passed on to prices incompletely. Our explanation is based on the assumption of external, relative, deep habits in consumption. When habits are deeply rooted, firms face demand functions that depend not only on the current price but also on the stock of habits, which in turn is a function of all past sales of the good the firm produces. The firm's optimal pricing problem becomes dynamic and firms no longer set prices so as to equate marginal revenue to marginal costs in the current period. Instead, firms take into account the future marginal revenues that will be generated by a sale today due the fact that a current sale increases the future stock of habits.

We show that an unanticipated firm-specific cost shock leads to incomplete pass-through (or a decline in markup) of about 20 percent, and that an anticipated cost shock is associated with incomplete pass-through of about 50 percent.

Our theoretical analysis is concerned with the pass-through of firm-specific marginal cost shocks. The predictions of our model could be applied to interpret the vast empirical evidence on incomplete pass-through of nominal exchange-rate changes. The reason why cost passthrough and exchange-rate pass-through may appear to be related can best be illustrated with an example. Consider a German exporter of cars to the United States. Assume that marginal cost of that exporter are in Euro and are unaffected by a change in the Euro-dollar

exchange rate. Further assume that the exporter faces no local or distribution costs in the United States. Then one can express period profits of the German exporter in U.S. dollar terms as $\left(P_{i t}-M C_{i t} / S_{t}\right) q_{i t}$, where $P_{i t}$ is the dollar price at which the German exporter offers the car for sale in the United States, $M C_{i t}$ is the marginal cost denominated in Euro, $S_{t}$ 
is the Euro price of one dollar, and $q_{i t}$ is the demand for a particular type of German car in the United States. Suppose now that the U.S. dollar depreciates, that is, $S_{t}$ decreases. Then one could interpret the U.S. dollar depreciation as an increase in marginal cost of the exporter of German cars, and one might consider using our deep habit model to study the effects of a dollar depreciation on the dollar price of the German car in the U.S. market.

In interpreting an exchange rate change as a firm-specific marginal cost shock, the following issues emerge. One of the assumptions we maintain throughout the paper is that all variables that are not firm-specific such as the aggregate price level and the level of aggregate demand are unaffected by the firm-specific marginal cost shock. This assumption may not be compelling if one were to identify a marginal cost shock with an exchange-rate change. For the exchange-rate change may have an effect on the aggregate price level and on aggregate demand, $P_{t}$ and $x_{t}$, respectively, in terms of the notations of the demand function given in equation (4). Furthermore, we assume that the discount factor that firms apply to future profits, $\beta$, is unaffected by the firm-specific marginal cost change. If the source of the marginal cost change is an exchange-rate rate change, then this assumption might be incorrect. For example, Froot and Klemperer (1989) in their classic study on exchange rate pass-through attribute part of the observed incomplete exchange-rate pass-through to an interest rate effect, whereby a dollar depreciation leads to an increase in the discount factor, increasing the rate of return on investment in market share. When firms invest more in market share they let their profit margins dip. And lower profit margins are associated with lower markups or incomplete pass-through.

At the same time, given the encouraging results on limited cost pass-through presented in this paper, we believe that it would be a worthwhile project to estimate our model on firm-specific price and cost data. 


\section{References}

Froot, Kenneth A. and Paul Klemperer, "Exchange Rate Pass-Through When Market Share Matters," American Economic Review 79, September 1989, 637-654.

Goldberg, Pinelope K., "Product Differentiation and Oligopoly in International Markets: The Case of the US Automobile Industry," Econometrica 63, July 1995, 891-951.

Hellerstein, Rebecca, "Who Bears the Cost of a Change in the Exchange Rate? The Case of Imported Beer," Federal Reserve Bank New York Staff Report \#179, February 2004.

Kadiyali, Vrinda, "Exchange Rate Pass-Through for Strategic Pricing and Advertising: An Empirical Analysis of the US Photographic Film Industry," Journal of International Economics 43, November 1997, 437-461.

Klemperer, Paul, "Markets With Consumer Switching Costs," Quarterly Journal of Economics 102, May 1987, 375-394.

Klemperer, Paul, "Competition when Consumers have Switching Costs: An Overview with Applications to Industrial Organization, Macroeconomics, and International Trade," Review of Economic Studies 62, 1995, 515-539.

Kleshchelski, Isaac and Nicolas Vincent, "Market Share and Price Rigidity," manuscript, Northwestern University, January 2007.

Nakamura, Emi, "Accounting for Incomplete Pass-Through," manuscript, Harvard University, November 2006.

Phelps, Edmund S. and Sidney G. Winter, "Optimal Price Policy under Atomistic Competition," in Edmund S. Phelps, Ed., Microeconomic Foundations of Employment and Inflation Theory, New York, NY: W.W. Norton, 1970, 309-337.

Ravn, Morten, Stephanie Schmitt-Grohé, and Martín Uribe, "Relative Deep Habits," manuscript, Duke University, May 5, 2005.

Ravn, Morten, Stephanie Schmitt-Grohé, and Martín Uribe, "Deep Habits," Review of Economic Studies 73, January 2006, 195-218. 